\title{
Assessment of the Semi-Adiabatic Temperature Rise of Mass Concrete Containing Bagasse Ash
}

\author{
Amanuel Bersisa*, Adil Zekaria \\ Civil and Environmental Engineering, Addis Ababa Institution of Technology, Addis Ababa, Ethiopia \\ Email address: \\ amanuel.bersisa@aait.edu.et (A. Bersisa), adil.zekaria@aait.edu.et (A. Zekaria) \\ ${ }^{*}$ Corresponding author
}

To cite this article:

Amanuel Bersisa, Adil Zekaria. Assessment of the Semi-Adiabatic Temperature Rise of Mass Concrete Containing Bagasse Ash. Journal of Civil, Construction and Environmental Engineering. Vol. 6, No. 4, 2021, pp. 110-119. doi: 10.11648/j.jccee.20210604.12

Received: July 16, 2021; Accepted: August 4, 2021; Published: August 27, 2021

\begin{abstract}
Previous studies show that pozzolan materials are a wise choice for retarding significant heat in mass concrete placements. This research aims at studying the early age thermal property of concrete containing bagasse ash under different ambient temperatures. Moreover, the compressive strength of concrete specimens with varying ratios of the mix is assessed. Semi-adiabatic temperature rise data of four different concrete mixtures (containing pure Portland cement, $6.5 \%, 13 \%$, and $20 \%$ dosage of bagasse ash by volume) are determined. Concrete specimens of size $30 \mathrm{~cm} * 30 \mathrm{~cm} * 40 \mathrm{~cm}$ were cast and insulated using Styrofoam. The temperature measurement is taken at three different locations for every 30 minutes of interval. The influence of ambient temperature on specimens' early age thermal response is studied using a temperature chamber capable of simulating $25.15^{\circ} \mathrm{C}, 35.54^{\circ} \mathrm{C}$, and $43.77^{\circ} \mathrm{C}$ average ambient temperatures. The results indicated that bagasse ash could replace the cement up to an optimum replacement level of 10 percent even if an early age strength drop is observed. The experiment revealed that the bagasse ash in the concrete mixture shift the temperature rise-time profile, reduces the total heat of hydration, and decreases the thermal gradient in the specimens. The peak temperature gauge of all mixes elevated as the ambient temperature increased, but mixtures containing bagasse ash show a slower heat liberation rate relative to the control group. The study proves pozzolan reaction is slow, releasing heat over a long period and not taking place early. It has merit in a massive concrete placement where cooling can lead to cracking following a significant temperature rise.
\end{abstract}

Keywords: Thermal Cracking, Mass Concrete, Heat of Hydration, Ambient Temperature, Sustainable Concrete, Bagasse Ash

\section{Introduction}

Cracking in concrete structures are two types. Crack induced due to an external load considered in the conventional structural design calculation, and material type resulted in temperature differential or restrained condition. The hydration of cement is an exothermic reaction. In the high-volume concrete section, the hydration heat accumulated at the interior part of the concrete structure will not dissipate fast. There will be a rapid loss of heat from the surface of the section to the surrounding. The uneven temperature distribution throughout the material is known as a thermal gradient. It results in non-uniform volume change across the element's cross-section, thereby inducing stresses to cause thermal cracks [1-3].

Mass-concrete is stated as "any volume of concrete with dimensions large enough to require that measures be taken to cope with heat generation from the hydration of the cement and attendant volume change to minimize cracking" [4]. Another precaution for Mass-concrete is if a thinner section uses higher heat-generating concrete mixing, higher cementitious materials content, or fast hydrating mixtures [5]. Mass concrete is also be taken by hydration-heat diffusion length: the gauge length related to thermal diffusivity and characteristics hydration time. It will vary with the degree of hydration and temperature. Structural concrete is then defined as Mass-concrete when the maximum distance of any point in the concrete to its nearest free surface is greater than the hydration heat diffusion length [6].

The amount of heat generated in the concrete depends on the cement type, fineness of the binder, chemical composition, casting temperature, and ambient temperature [3, 7]. Pre-cooling (using chilled mixing water) and post-cooling (using embedded cooling pipes) are methods to mitigate 
thermal cracking. However, Low-heat generating concrete mixture is always a wise choice for mass concrete to minimize potential thermal hazards. The proper use of the new pozzolan has advantages in the reduction of the heat of hydration. Moreover, the addition of pozzolan material in a concrete mixture undergoes a chemical reaction with calcium hydroxide $\mathrm{Ca}(\mathrm{OH})_{2}$ and creates an additional C-S-H gel to ensure strength development [8-10]. The pozzolan reaction generates less heat than ordinary Portland cement because the response is similar to a $\mathrm{C}_{2} \mathrm{~S}$ reaction. [7, 11, 12]. Low-heat binders such as class-F fly ash, Bagasse ash, or Slug as cement replacements and the minimum amount of total cementitious materials can reduce the temperature evolution when there is a thermal cracking risk $[3,13]$.

Bagasse ash is a by-product of the sugar industry collected after the bagasse is used as fuel in boilers of sugar mills for the cogeneration process. It is disposed of locally, which causes severe environmental problems. A sugar factory produces nearly three tons of wet bagasse ash from every ten tonnes of sugarcane $[14,15]$. The combustion yields ashes containing high amounts of unburned matter like silica and alumina oxides [16].

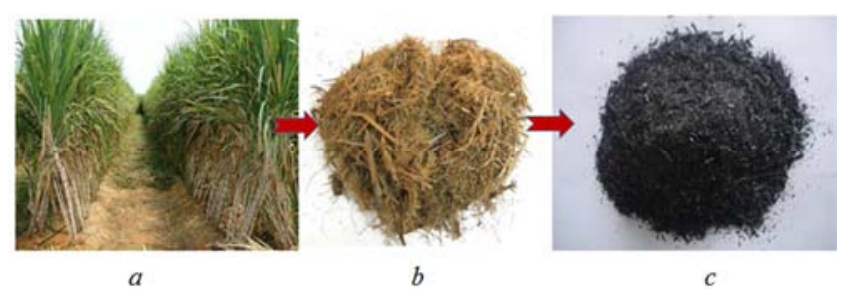

Figure 1. a, Sugarcane b, Bagasse c, Bagasse ash.

X-Ray Diffraction (XRD) study revealed the presence of quartz and cristobalite. The main chemical composition of bagasse ash was $65 \%$ of $\mathrm{SiO}_{2}, 3.9 \%$ of $\mathrm{CaO}$, and $2.0 \%$ of $\mathrm{K}_{2} \mathrm{O}$, with ignition loss (LOI) of $10.5 \%$ [17].

The modern construction industry is researching pozzolan alternatives. These new pozzolans could come as by-products from different sectors, usually accompanied by low prices, but their efficiency is questionable in most cases. Researches are undertaken to examine the performance of this pozzolan in a concrete mixture. This examination primarily focuses on mechanical properties.

Bayapureddy, Muniraj, and Mutukuru 2020 [18] have conducted an experimental study on the Compressive and Tensile strength of concrete containing this bagasse ash. Strength gain is observed in 5\%,10\%, and $15 \%$ replacement of sugarcane bagasse ash in cement and maximum at $15 \%$ decreased further. Water absorption decreased in all samples containing sugarcane bagasse ash compared to OPC. In a similar study, well-burnt bagasse ash up to $20 \%$ can optimally replace high-strength Portland cement without any adverse effect on the desirable properties of concrete [19].

The presence of bagasse ash enhanced the compressive strength development of concrete specimens up to a $10 \%$ replacement level [11]. Mangi et al. [20] found that Bagasse ash concrete gives a higher compressive strength than the control group strength with five percent optimal replacement. The concrete containing SCBA requires less water to achieve the same workability as the conventional concrete mix. The water demand decreased with an increase in SCBA percentage replacement [16]. Similarly, Mangi et al. [20] state that replacing cement with SCBA increases the workability of fresh concrete; therefore, using a super-plasticizer is not essential. In contrast, the percentage of the replacement materials increases for both laterite and sugarcane bagasse ash, the slump value decreases, making concrete less workable [21].

In addition to the mechanical properties, the thermal properties of those industrial waste pozzolans are studied. In 2017, the study for the appliance of bagasse ash in rigid pavements identified bagasse ash to attenuate the total heat of hydration up to $20 \%$ [11].

The environmental temperature is essential in determining the heat of hydration. Cement hydration at higher ecological temperatures is accelerated at early ages but decelerated later [9]. Since seasonal change becomes significant, it should have to be considered mass concrete, structures that have to be constructed for an extended period. Factors like ambient temperature affect the rate of hydration and heat evolution of both pozzolan and cement materials. Therefore, studies should be carried out on different environmental conditions before using them as a cement replacement material.

The research objective is to study the effect of ambient temperature on the heat evolution of concrete containing bagasse ash. The experimental program involves a semi-adiabatic temperature rise experiment for concrete specimens with different bagasse ash proportions. In addition to the former investigation, a compressive strength test is conducted to assess the strength development. This research examines the probability of bagasse ash usage in mass concrete. The study was quite intensive, and the temperature data reading was difficult since it involves night sessions.

\section{Material and Methods}

\subsection{Materials}

The fine aggregate is natural river sand, and the coarse aggregate is crushed stone. After proper washing for removing the silt on the surface, the material is placed in a plastic bag; it helps preserve the water content.

The physical characterization of coarse and fine aggregate was done per the ASTM standard at the Addis Ababa University material laboratory. Before any experimental programs, the proper sampling method is followed according to ASTM D75/D75M - 19. Table 1 shows the physical characterization result. 
Table 1. Coarse and Fine Aggregate Physical Properties.

\begin{tabular}{llll}
\hline Property & Standard & Fine Aggregate & Coarse Aggregate \\
\hline Fineness Modules & ASTM C 136 84 & 2.61 & - \\
Nominal Aggregate size & ASTM D 448 - 98 & - & $25 \mathrm{~mm}$ \\
Dry Rodded Unit Weight & ASTM C 29-97 & $1524.39 \mathrm{~kg} / \mathrm{m}^{3}$ & $1598.65 \mathrm{~kg} / \mathrm{m}^{3}$ \\
Bulk SG & ASTM C 127 - 88 & 2.41 & 2.75 \\
Absorption Capacity & ASTM C 127 - 88 & 2.74 & 1.52 \\
Moisture Content & ASTM C 566- 84 & 1.62 & 0.81 \\
\hline
\end{tabular}

According to ASTM C-33-01, the upper and lower bound of percentage cumulative passing for fine and coarse aggregate in each sieve size is specified. The fine and coarse aggregate satisfies ASTM C-33-01 requirement.

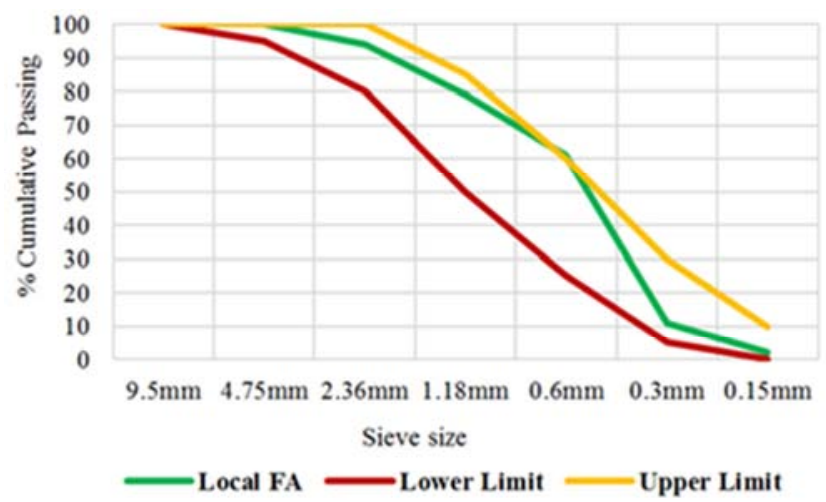

Figure 2. Grading Curve of Fine Aggregate.

Figure 3 shows the coarse aggregate gradation adjacent to the upper and lower boundaries specified at ASTM-33-01.

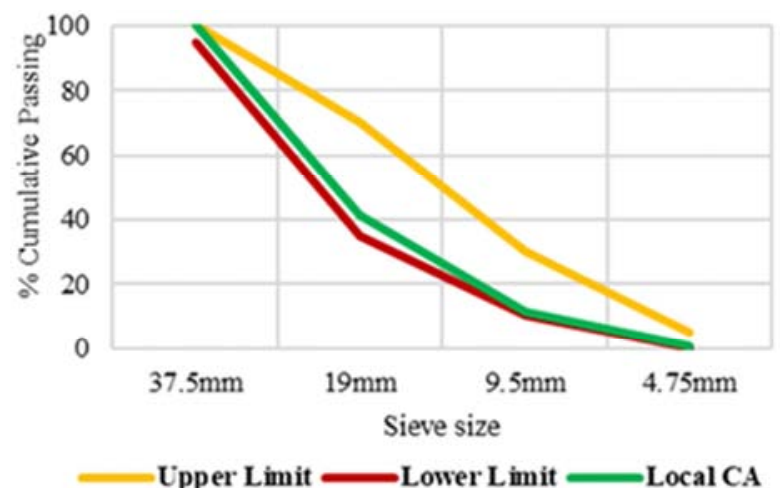

Figure 3. Grading Curve of Coarse Aggregate.

The cement used is Portland cement type-1 (42.5-N), and the Bagasse is from a bughouse in the Wonji sugar factory. The specific surface area using the Blaine air-permeability apparatus gives a value of $3177.3 \mathrm{~cm}^{2} / \mathrm{g}$. The specific gravity of the cement and bagasse ash is 2.14 and 3.15 respectively.

The properties of pozzolan pastes are determined by complex relationships of interdependent variables, including surface area, particle size, and chemical composition. Pozzolan assets might be dependent on the fineness of bagasse ash. As long as the bagasse ash composition is fine and free from unburned carbon particles, it could ensure the early age mechanical properties of the concrete.

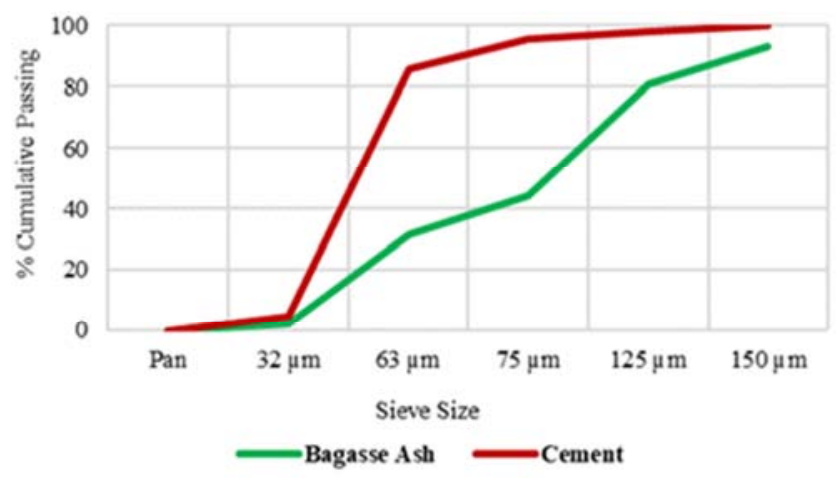

Figure 4. Grading Curve for Cement and Bagasse ash.

Complete silica analysis was carried out at Ethiopian geological and survey, and the result is tabulated below.

Table 2. Chemical Characterization of Cement and Fly ash

\begin{tabular}{llll}
\hline Compounds & $\begin{array}{l}\text { Bagasse Ash } \\
(\%)\end{array}$ & $\begin{array}{l}\text { Cement } \\
(\%)\end{array}$ & Remark \\
\hline $\mathrm{SiO}_{2}$ & 68.6 & 26.62 & \\
$\mathrm{Al}_{2} \mathrm{O}_{3}$ & 9.04 & 6.08 & \\
$\mathrm{Fe}_{2} \mathrm{O}_{3}$ & 5.24 & 4.82 & \\
$\mathrm{CaO}$ & 1.52 & 55.30 & \\
$\mathrm{LOI}$ & $7.91<10$ & 3.43 & \\
$\mathrm{SiO}_{2}+\mathrm{Al}_{2} \mathrm{O}_{3}+\mathrm{Fe}_{2} \mathrm{O}_{3}$ & $83.18>75$ & - & ASTM-C 618-00 satisfied \\
\hline
\end{tabular}

\subsection{Mixture Design}

Four concrete mixtures are designed using ACI 211.1-91 standard procedure. The control group is proportioned to have a specified compressive strength of $25 \mathrm{MPa}$ (Target compressive strength, $33 \mathrm{MPa}$ ). Table 3 shows the quantity of each ingredient for the control group. Partial replacement of cement using bagasse ash is volume-based. ACI 211.1-91, equation 1, was used for calculating the weight of pozzolan material.

$$
F w=\frac{1}{1+\left(3.15 / \mathrm{G}_{\mathrm{p}}\right)\left(\frac{1}{\mathrm{f}_{\mathrm{v}}}-1\right)}
$$

Where: $\mathrm{F}_{\mathrm{w}}=$ Weight of pozzolan

$\mathrm{G}_{\mathrm{p}}=$ Specific gravity of pozzolan

$\mathrm{f}_{\mathrm{v}}=$ Percentage volume replacement level 
Table 3. Summary of Mix-Design.

\begin{tabular}{lllllll}
\hline Mixture Id. & Bagasse ash $\left(\mathbf{k g} / \mathbf{m}^{\mathbf{3}}\right)$ & Cement $\left(\mathbf{k g} / \mathbf{m}^{\mathbf{3}}\right)$ & Fine Aggregate $\left.\mathbf{( k g} / \mathbf{m}^{\mathbf{3}}\right)$ & Coarse Aggregate $\left.\mathbf{( k g} / \mathbf{m}^{\mathbf{3}}\right)$ & $\mathbf{W a t e r}\left(\mathbf{k g} / \mathbf{m}^{\mathbf{3}}\right)$ & $\mathbf{W} / \mathbf{B ~ B y ~ V o l u m e}$ \\
\hline BA-0 & 0 & 334.5 & 763.03 & 1046.52 & 190 & 0.56 \\
BA-6.5 & 15.08 & 312.76 & 763.03 & 1046.52 & 190 & 0.56 \\
BA-13 & 30.82 & 291.02 & 763.03 & 1046.52 & 190 & 0.56 \\
BA-20 & 48.36 & 267.6 & 763.03 & 1046.52 & 190 & 0.56 \\
\hline
\end{tabular}

Where: - BA- $0=$ control group $100 \%$ OPC

BA- $6.5=6.5 \%$ of bagasse ash and $93.5 \%$ OPC

BA- $13=13 \%$ of bagasse ash and $87 \%$ OPC

BA- $20=20 \%$ of bagasse ash and $80 \%$ OPC

BA: Bagasse ash, OPC: ordinary Portland cement

The weight-based replacement creates a variation in paste volume since cement's specific gravity is greater than bagasse ash. So to ensure equal paste, volume-based replacement is adopted.

\subsection{Test Setup and Procedure}

\subsubsection{Compressive Strength}

Compressive strength is estimated by dividing the maximum load by the cross-sectional area in a compression test. After the concrete is mixed uniformly per ASTM C-192, placing the concrete into the $15 \mathrm{~cm} * 15 \mathrm{~cm} * 15 \mathrm{~cm}$ cube molds is done using a scoop and shovel. The specimens were removed from the mold at $24 \pm 8$ hours and directly placed in a water container to provide a consistent curing condition. A universal testing machine determined cube specimens' 1, 2, 3, 7, and 28-day strength. The compressive strength of concrete samples of the same concrete mix might deviate, so an average value of three samples is reported.

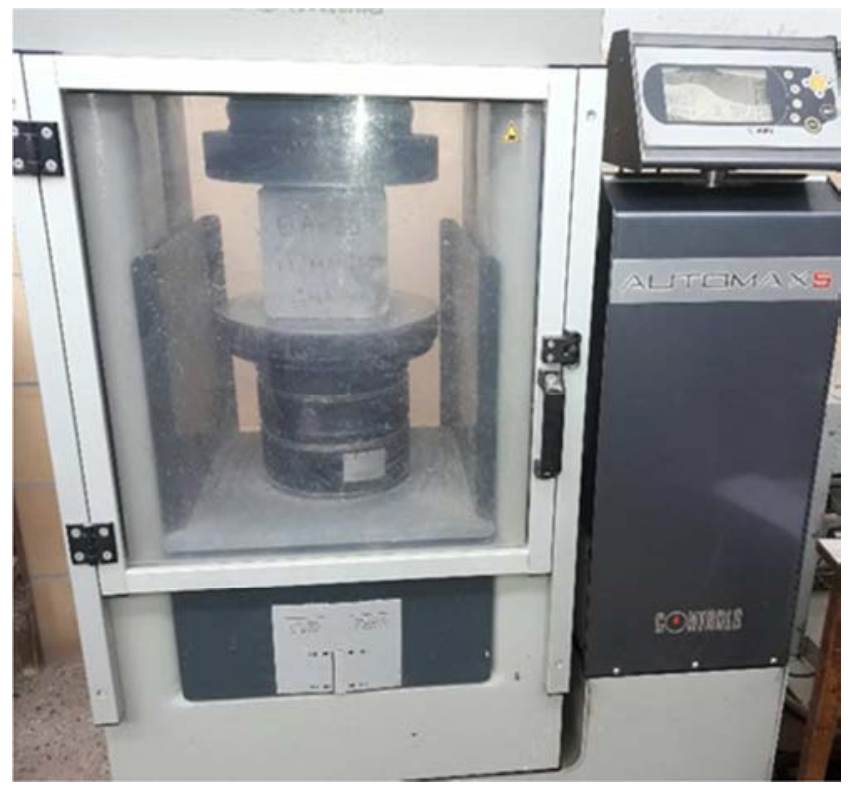

Figure 5. Compressive strength test.

\subsubsection{Thermal Property}

The heavily insulated adiabatic experiment can prevent heat loss. However, high set-up costs and the large sample size could make the testing program less practical than a semi-adiabatic experiment. So a semi-adiabatic temperature rise experiment is used to record the hydration heat. This experiment is similar to adiabatic temperature rise but with a slight heat loss with time [9]. For the semi-adiabatic investigation, molds are made from plywood $30 \mathrm{~cm} * 30 \mathrm{~cm} * 40 \mathrm{~cm}$ cube in size. The mold is insulated using $10 \mathrm{~cm}$ thickness Styrofoam to prevent diffusion of heat to the surrounding.

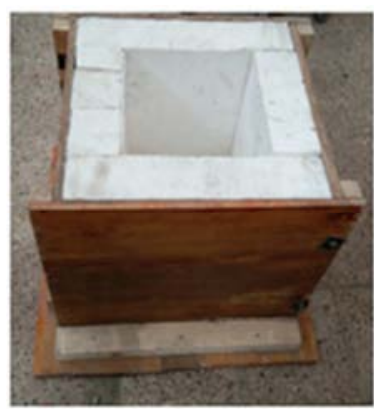

(a)

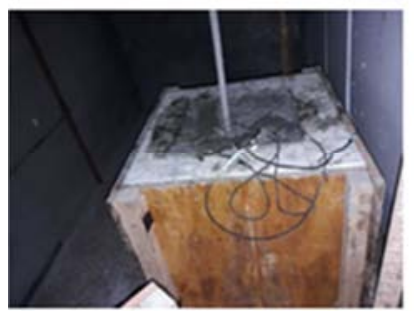

(c)

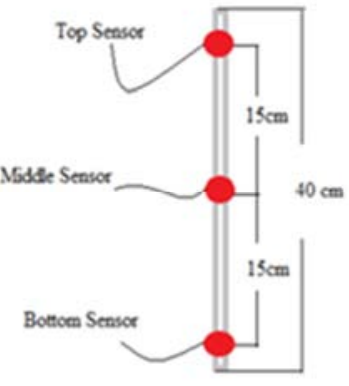

(b)

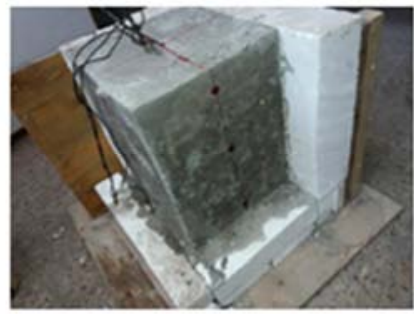

(d)
Figure 6. a, concrete mold b, location of temperature sensor $c$, under experiment $d$, after experiment.

The upper part of the concrete mold is left open to simulate the effect of ambient temperature. Three temperature sensors located at the top, center, and bottom of the specimen are used to read temperature data for each 30-minute interval using thermocouples until the maximum heat is perceived. The temperature reading took more than six days, including night sessions. For three different ambient temperatures and four different replacement ratios, twelve specimens were cast.

\subsubsection{Ambient Temperature}

The semi-adiabatic experiment is conducted under three different ambient temperatures: $25.15^{\circ} \mathrm{C}, 35.54^{\circ} \mathrm{C}$, and $43.77^{\circ} \mathrm{C}$. Figure 7 shows the temperature histories obtained from the temperature chamber. 

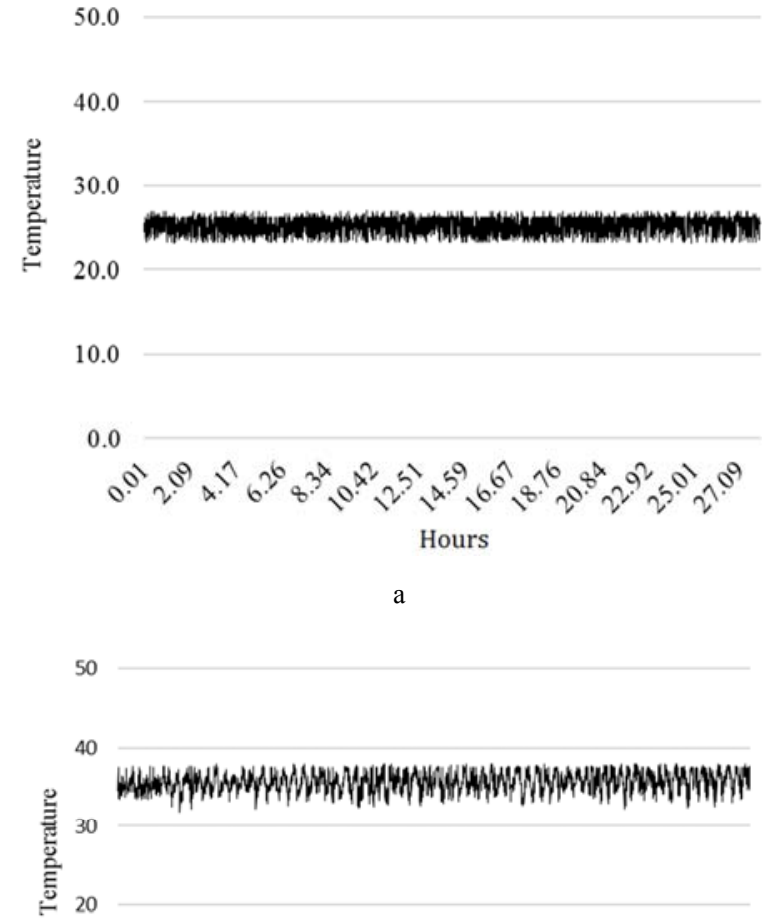

10

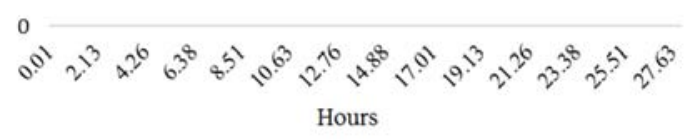

b

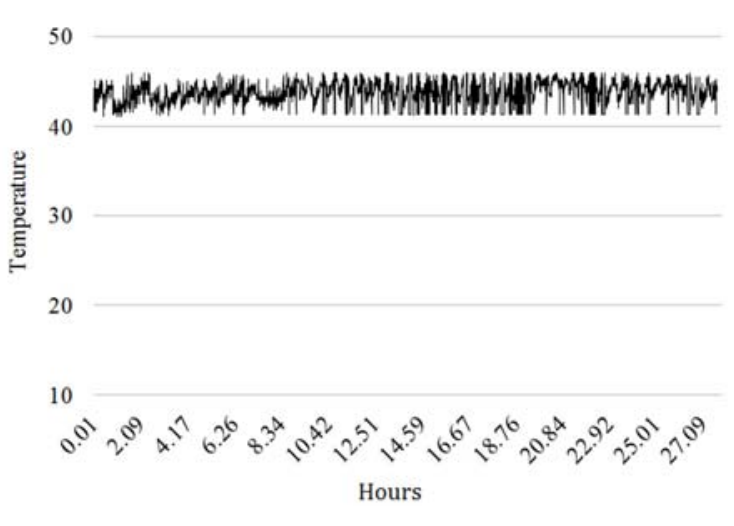

c

Figure 7. Temperature histories of the chamber at different ambient conditions.

\section{Result and Discussion}

\subsection{Compressive Strength}

The strength development and heat liberation rate are the main driving forces that control early age thermal cracking. Thus, in addition to the semi-adiabatic test, a compressive strength development experiment is included. Figure 8 shows the average strength result.

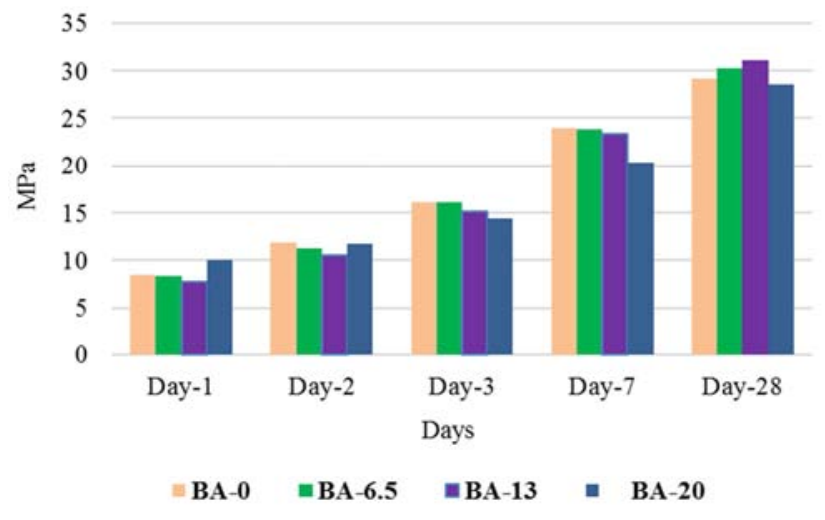

Figure 8. Compressive strength development.

Until day-7, concrete mixtures with bagasse ash possess lower compressive strength compared to full cement concrete. For example, the first-day compressive strength of concrete containing $6.5 \%$ and $13 \%$ of the ash is dropped by $1.64 \%$ and 9.3\% sequentially. Similarly, the second-day crush strength drops by $5.4 \%$ and $11.9 \%$ for $6.5 \%$ and $13 \%$ replacement levels. In contrast, there was an enhancement of crush strength on the following days. The strength enhancement is shown as the age of testing increases. For example, the drop in strength on the seventh day was only $0.62 \%$ and $2.25 \%$ for the aforementioned replacement. The early age strength drop with a concrete mixture containing pozzolan is shown in many studies.

In contrast, some studies suggest that bagasse ash enhances early age strength development $[11,17,19,22]$. The difference in the early age strength development between studies might arise from the type of replacement, the properties of local bagasse ash, the cement type, etc. In a weight-based replacement, the paste volume increase with an increment of replacement level. An additional paste volume has an impact on strength development. In this study, to control the resulted paste from all mixtures, the volume-based replacement is used.

On the 28th day, the strength of concrete specimens contains $6.5 \%$, and $13 \%$ of Bagasse ash is greater than the control group by $3.46 \%$ and $6.64 \%$. First, the strength gain over time is highly dependent on the interfacial transition zone (ITZ). The more densified ITZ implies the more strength. Utilizing pozzolan with finer particle size or high pozzolanic reactivity is among the methods to enhance ITZ property [26]. Over time, the strength gain might result from the pozzolan reaction in the interfacial transition zone that densifies the aggregate and binder matrix. The improvement of the microstructure of the interface zone by using pozzolan materials is also the ability of the tiny Bagasse ash particles to fit in between cement particles [24]. Secondly, the initial rapid release of calcium hydroxide into the solution leaves an outer layer of calcium silicate hydrate, perhaps $10 \mathrm{~nm}$ thick. This layer impedes further hydration so that, for some time after that, very little hydration takes place [25]. The pozzolan reaction will absorb the calcium hydroxide, which acts as a thin film in the remaining cement compounds. It will indeed help to facilitate the hydration process. Thirdly, the bagasse ash also acts as an inert filler between the voids [26, 27]. 


\subsection{Early-age Thermal Properties}

The specimens were insulated in all directions except the upper part, which was left open intentionally. Thus, the peak temperature was at the bottom part of the specimens. The insulation allows the interior concrete to reach a higher temperature by slowing the heat radiation to the surrounding. The peak temperature will fall through time, and it will have the same magnitude as the ambient. The peak temperature gauges for each replacement level under different ambient conditions and the corresponding time of measurements are summarized in table 4 .

Table 4. Peak Temperature in Concrete Specimens.

\begin{tabular}{|c|c|c|c|c|c|c|c|}
\hline \multirow{3}{*}{ Mixture Code } & \multirow{3}{*}{ Location } & \multicolumn{6}{|c|}{ Ambient Temperature } \\
\hline & & \multicolumn{2}{|c|}{$25.15^{\circ} \mathrm{C}$} & \multicolumn{2}{|l|}{$35.54^{\circ} \mathrm{C}$} & \multicolumn{2}{|c|}{$43.77^{\circ} \mathrm{C}$} \\
\hline & & Hr. & Tem. $\left({ }^{\circ} \mathrm{C}\right)$ & Hr. & Tem. $\left({ }^{\circ} \mathrm{C}\right)$ & Hr. & Tem. $\left({ }^{\circ} \mathrm{C}\right)$ \\
\hline \multirow{3}{*}{ BA-0 } & Top & 17 & 36.9 & 14.5 & 38.2 & 17.5 & 47.5 \\
\hline & Middle & 16.5 & 41.2 & 15.5 & 43.7 & 18.5 & 48.9 \\
\hline & Bottom & 16.5 & 43.9 & 16.5 & 47 & 19 & 51.4 \\
\hline \multirow[b]{2}{*}{ BA- 6.5} & Top & 17.5 & 35.5 & 15.5 & 37.3 & 19 & 45.5 \\
\hline & Middle & 16.5 & 38.5 & 17 & 42.2 & 21 & 46.1 \\
\hline \multirow{3}{*}{ BA-13 } & Top & 18 & 33.8 & 16 & 36.7 & 20 & 43.5 \\
\hline & Middle & 17.5 & 36.4 & 16.5 & 40.2 & 21.5 & 44.8 \\
\hline & Bottom & 18 & 39.3 & 18.5 & 42.7 & 23 & 46.4 \\
\hline \multirow{3}{*}{ BA-20 } & Top & 20 & 32.3 & 17 & 35.2 & 16.5 & 39.9 \\
\hline & Middle & 19.5 & 35 & 18.5 & 38.9 & 18.5 & 40.8 \\
\hline & Bottom & 19 & 37.3 & 20 & 41.4 & 19 & 43 \\
\hline
\end{tabular}

\subsubsection{The Effect of Ambient Temperature on Heat Evolution}

The peak temperature measured at the bottom part of the control specimen increased by $17 \%$ as the ambient temperature changed from $25.15^{\circ} \mathrm{C}$ to $43.77^{\circ} \mathrm{C}$. Higher ambient temperature creates a higher core temperature, which will facilitate the hydration of cement and result in the maturity of concrete. Even if the early age strength is enhanced due to higher ambient temperature, later the concrete will expand and cracking will occur associated with the delayed formation of the mineral ettringite, termed delayed ettringite formation. The duration to attain a peak temperature of $43.9^{\circ} \mathrm{C}$ shifts from 16.5 hours to 12.5 hours. The hydration reactions progress faster at early ages with an increase of higher temperature $[28,29]$.

Methods used to control temperature differences are more passive, such as proper formwork removal time and coordinating the construction schedule to align with cooler ambient temperatures [30]. This study supports the above hypothesis; it has clearly shown the peak temperature is less in lower ambient temperature. Even the ultimate temperature of concrete specimens contain $6.5 \%, 13 \%$, and $20 \%$ was much lower when compared with neat cement concrete, but all concrete mixtures were under the influence of ambient temperature.

Temperature profile spectacles, the first 4-6 hours of hydration were slow for all mixes at $25.15^{\circ} \mathrm{C}$ ambient temperature. The control group reaction accelerates even for the first 2-3 hours as the ambient temperature increases. In contrast, the mixture contains $13 \%$ and $20 \%$ of the bagasse ash shows a relatively slow heat liberation rate at higher ambient temperature (see figure 9, g-i). Rafat Siddique [8] states, the pozzolan reaction is slow, releasing heat over a long period and not taking place at the early age of hydration. Moreover, Kim and Wang [9] stated that the main peak temperature is primarily attributed to $\mathrm{C}_{3} \mathrm{~S}$. $\mathrm{C}_{3} \mathrm{~A}$ also possesses significant heat during hydration, so as the replacement level increases, those compositions will decrease, leading to a drop in temperature.
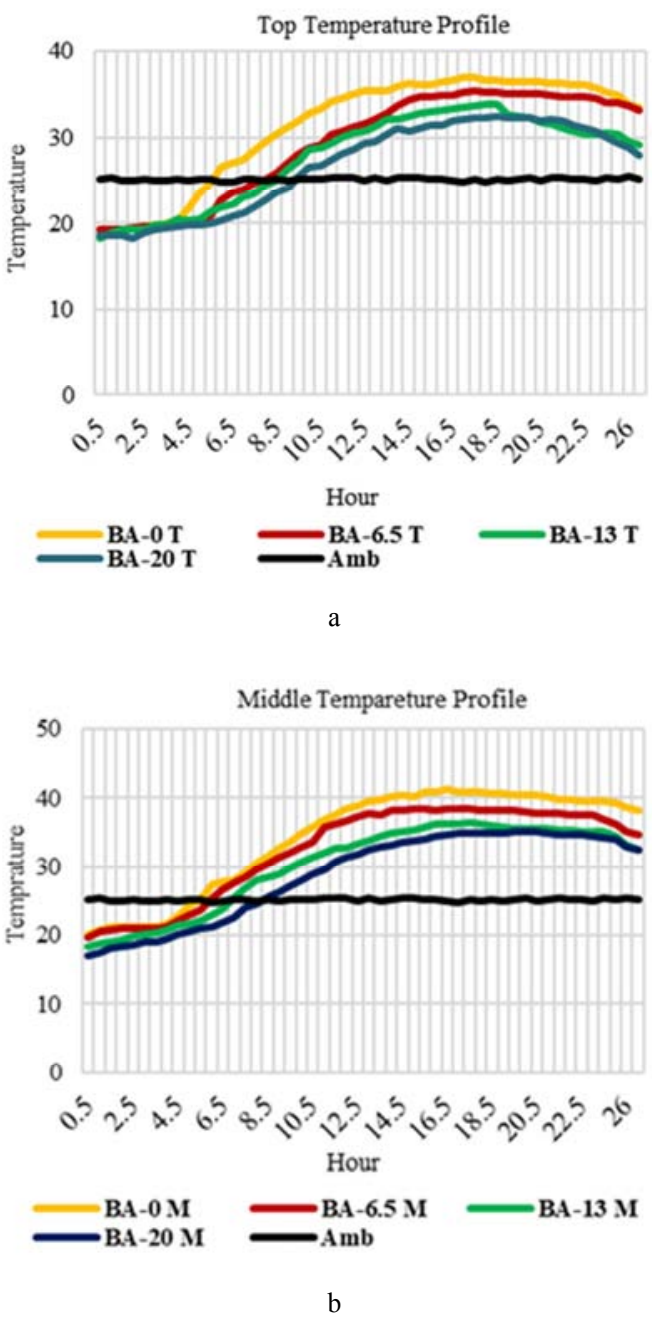

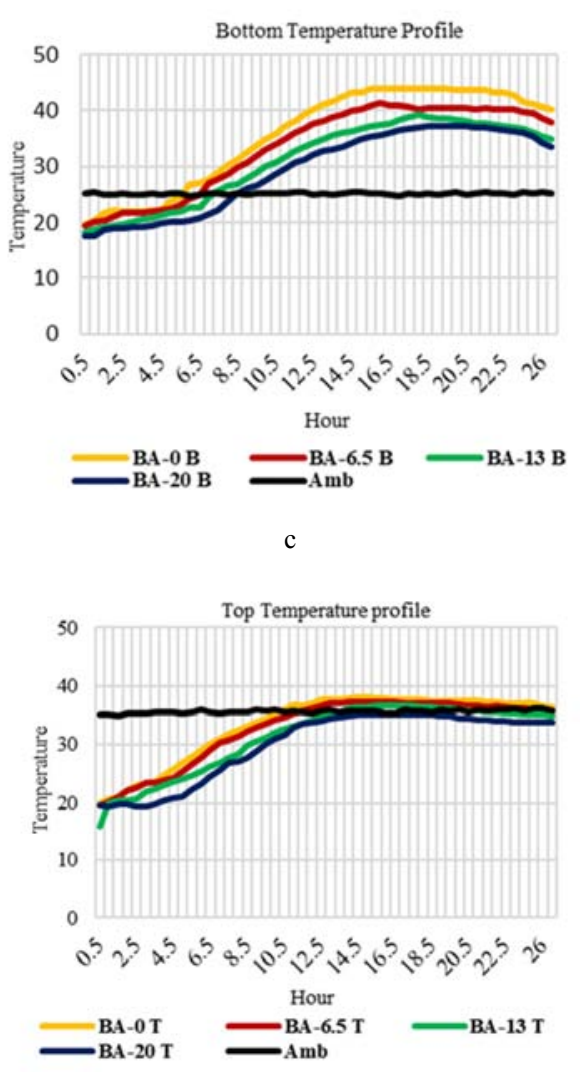

d

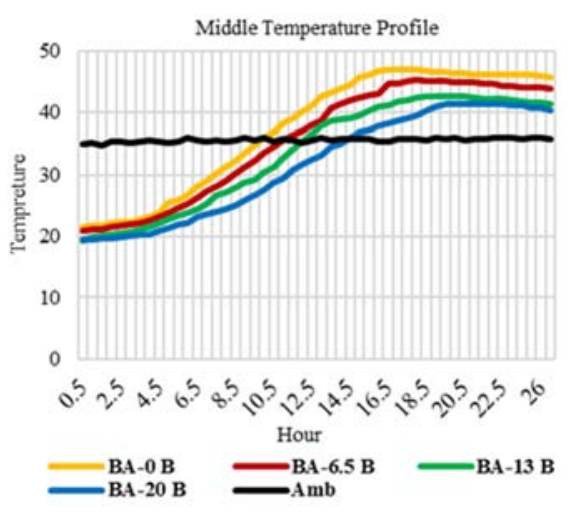

e

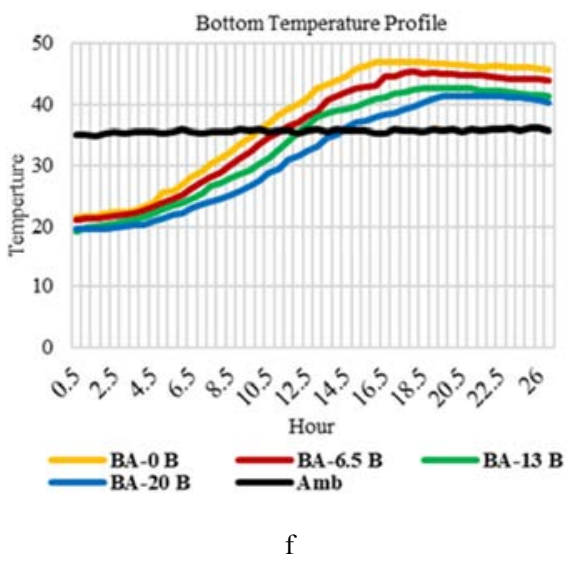

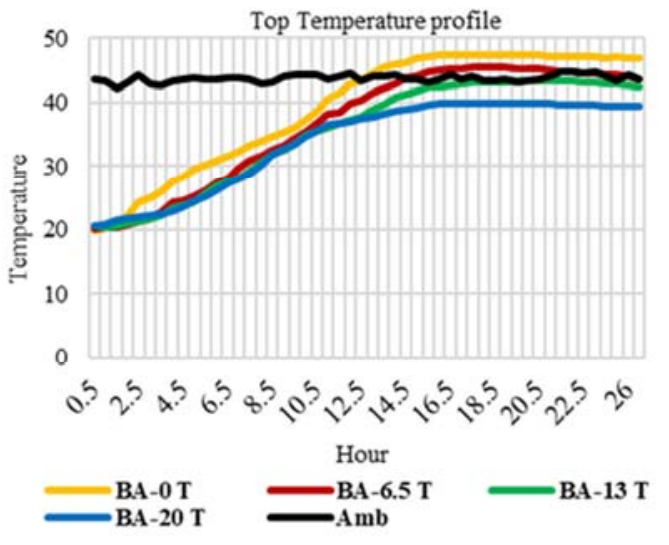

g

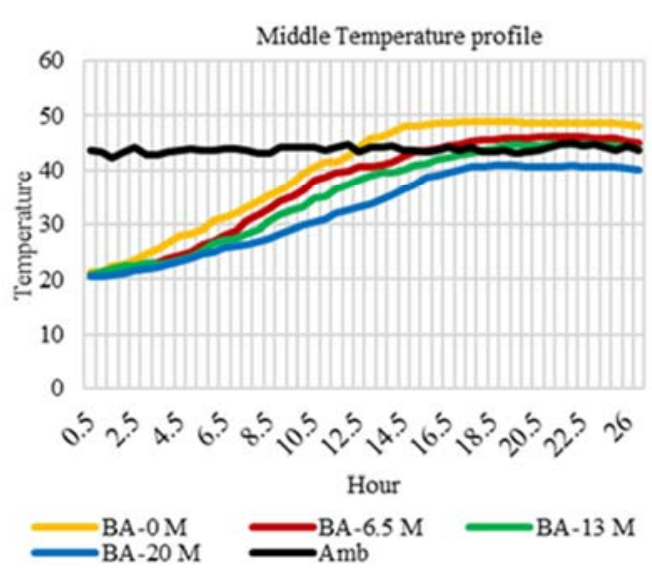

$\mathrm{h}$

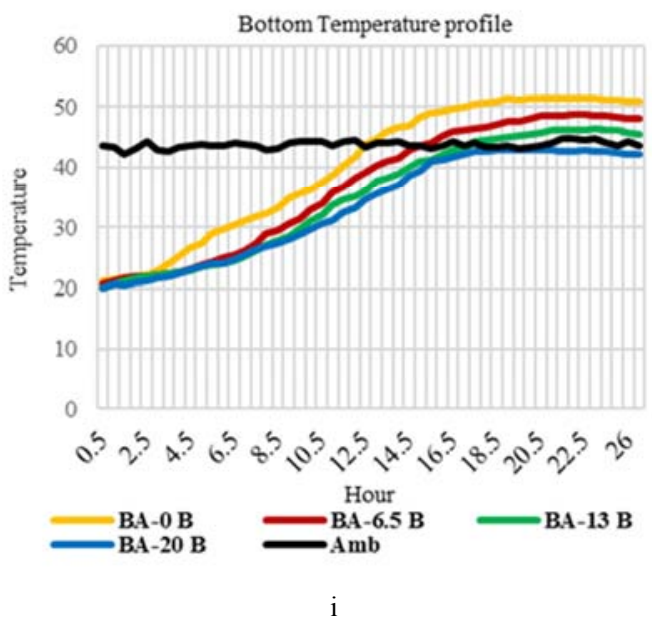

Figure 9. Temperature Profile of Concrete Specimens under Different Ambient Conditions.

The maximum temperature differential occurred when the maximum internal temperature occurred. The thermal gradient is relatively small in the bottom-middle portion of the concrete and steep towards the surface. Thus, it is clear that the temperature drop within a concrete specimen from bottom depth to the exposed surface is not linear, but rather most of the temperature drop occurs near the exposed concrete surface. Thus, the guideline for estimating thermal 
stress, formulated from a linear distribution, comes into question.

Following a change in the ambient from $25.15^{\circ} \mathrm{C}$ to $43.77^{\circ} \mathrm{C}$, the thermal gradient drop by $52 \%$ for all mixtures. In a hot environment, a temperature will not significantly radiate from the concrete surface to the surrounding. Besides, higher ambient transfers heat to the surface of the concrete specimen such that the thermal gradient between the top and bottom surface remains low. On the other hand, the thermal gradient increased up to $38 \%$ as the ambient changed from $25.15^{\circ} \mathrm{C}$ to $35.54^{\circ} \mathrm{C}$. Relatively, the intermediate ambient temperature may not significantly affect heating the top surface of the specimen. Still, it may facilitate the internal rate of hydration and increase the core temperature.

The temperature difference between the OPC concrete and ambient $\left(25.15^{\circ} \mathrm{C}\right)$ was $18.75^{\circ} \mathrm{C}$. In a cold environment, mass-concrete placement undergoes rapid heat loss to the surrounding, which is a reason for thermal gradient and thermal shocks (see figure 9, a-c). Even if concrete placement in cold weather is a crack mitigating strategy, it could have potential problems too. Early removal of formwork from the concrete surface can cause a sudden and extreme increase in the thermal gradient $[1,2]$. Under ambient temperatures of $35.54^{\circ} \mathrm{C}$ and $43.77^{\circ} \mathrm{C}$, the difference in concrete core and ambient temperatures are $11.46^{\circ} \mathrm{C}$ and $7.63^{\circ} \mathrm{C}$, respectively. It will make the concrete specimen go through an extended time for heat loss.

\subsubsection{The Effect of Bagasse Ash on the Heat Evolution}

The peak temperatures at $25.15^{\circ} \mathrm{C}$ ambient conditions are $43.9^{\circ} \mathrm{C}, 41.3^{\circ} \mathrm{C}, 39.3^{\circ} \mathrm{C}$ and $37.3^{\circ} \mathrm{C}$ for $0 \%, 6.5 \%, 13 \%$, and $20 \%$ replacement levels, and the corresponding time is 16.5 $\mathrm{hr}, 16 \mathrm{hr}, 18 \mathrm{hr}$, and $19 \mathrm{hr}$. The peak temperatures at $35.54^{\circ} \mathrm{C}$ ambient conditions are $47^{\circ} \mathrm{C}, 45.3^{\circ} \mathrm{C}, 42.7^{\circ} \mathrm{C}$, and $41.4^{\circ} \mathrm{C}$ for the replacement as mentioned earlier, and the corresponding time is $16.5 \mathrm{hr}, 18 \mathrm{hr}, 18.5 \mathrm{hr}$, and $20 \mathrm{hr}$. For $43.77^{\circ} \mathrm{C}$ ambient conditions, the peak temperatures gauge is $51.4^{\circ} \mathrm{C}, 48.7^{\circ} \mathrm{C}, 46.4^{\circ} \mathrm{C}$, and $43^{\circ} \mathrm{C}$ with a corresponding time of $19 \mathrm{hr}, 22 \mathrm{hr}, 23 \mathrm{hr}$, and $19 \mathrm{hr}$.

The presence of bagasse ash in the concrete mixture has dropped the total heat liberated from concrete mixtures. The decline in temperature is detected throughout the depth of all concrete mixtures containing bagasse ash. Replacing $20 \%$ cement using bagasse ash can drop the peak temperature of full cement concrete by $15 \%, 11.9 \%$, and $16.3 \%$ for $25.15^{\circ} \mathrm{C}, 35.54^{\circ} \mathrm{C}$, and $43.77^{\circ} \mathrm{C}$ ambient conditions respectively. In similar studies, Ribeiro, Yamamoto, and Yamashiki [31] had found that when 5\% of the bagasse ash is added to the mix, the peak temperature was $4.5^{\circ} \mathrm{C}$ lower than the control mixture. It has an advantage in a massive concrete placement where cooling can lead to cracking following a significant temperature rise.

Likewise, using bagasse ash at $6.5 \%$ and $13 \%$ replacement level reduces the overall temperature rise of the concrete even if the effect is less due to a lower replacement level. The temperature reduction is due to the inertness of the bagasse ash at an early age. Low calcium pozzolan (Similar to Class-C Fly ash) does not possess self-cementitious properties; therefore, it will not react rapidly with water and release excessive heat like ordinary Portland cement [8].

The thermal data shows, the duration to attain a peak temperature is extended, and there is a shift in the temperature rise curve. For instance, replacing $13 \%$ of cement using bagasse ash elongates the time required to reach $39^{\circ} \mathrm{C}$ internal temperature of the specimen by $6,3.5$, and 3 hours under $25.15^{\circ} \mathrm{C}, 35.54^{\circ} \mathrm{C}, 43.77^{\circ} \mathrm{C}$ ambient temperature respectively. Moreover, the time needed for the maximum thermal gradient also elongated in the presence of bagasse ash. Thermal cracking will occur due to large thermal gradients during the heat generation and subsequent cooling phases. The cracking tendency escalates as the time to reach this peak gradient decrease. Delay in the peak thermal gradient will provide additional time for concrete strength development before the thermal load is induced. Moreover, the thermal gradient is reduced as the cement-bagasse replacement level increases. For the $13 \%$ replacement level, the thermal gradient decreased by $21.4 \%, 31.81 \%$, and $25.64 \%$ for $25.15^{\circ} \mathrm{C}, 35.54^{\circ} \mathrm{C}$, and $43.77^{\circ} \mathrm{C}$ ambient temperatures respectively.

Figure 9 shows, the temperature gauge of all mixtures is not equal initially. Since all concrete casting was not at a time, there was a variation of casting temperature. Thus, concrete mixtures cast at lower ambient temperatures will eventually show a relatively slow reaction rate than high initial casting temperature. Choosing a relatively low ambient temperature for concrete casting is among the pre-cooling methods, and this study proves the same. The slow rate of heat liberation provides a longer time for the generated heat to dissipate and mitigate thermal cracking.

\section{Conclusion}

In this research, a semi-adiabatic temperature rise was determined for four cement to bagasse ash replacement ratios under three ambient conditions, and the following points conclude.

1) Concrete mixtures contain $6.5 \%$ and $13 \%$ bagasse ash satisfied the strength requirement compared with the control group. However, the early age strength development is retarded.

2) The presence of bagasse ash in concrete shifts the temperature-time curve. For instance, replacing $13 \%$ of cement using bagasse ash delays the time to reach $39^{\circ} \mathrm{C}$ internal temperature of the specimen by $6,3.5$, and 3 hours under $25.15^{\circ} \mathrm{C}, 35.54^{\circ} \mathrm{C}$, and $43.77^{\circ} \mathrm{C}$ ambient temperatures.

3) The concrete surface and ambient temperature difference is higher at lower ambient. Thus, cold area concrete placements should also get proper attention to mitigate thermal shock and rapid heat loss.

4) Heat evolution accelerated in high ambient temperature, and the high internal temperature is recorded. For 
example, the peak temperature measured at the bottom of the control specimen increased by $17 \%$ as the ambient temperature changed from $25.15^{\circ} \mathrm{C}$ to $43.77^{\circ} \mathrm{C}$.

5) Incorporating bagasse ash in concrete decreased the total heat of hydration and elongated the time required to attain the peak temperature by retarding early-age chemical reactions. For instance, the replacement of $20 \%$ of cement using bagasse ash drop the peak temperature of the neat cement concrete mixture by $15 \%, 11.9 \%$, and $16.3 \%$ for $25.15^{\circ} \mathrm{C}, 35.54^{\circ} \mathrm{C}$, and $43.77^{\circ} \mathrm{C}$ ambient temperatures.

\section{Recommendation}

While maintaining the benefit in the retarding heat of hydration, future research could be on thermal, mechanical, and chemical activation to enhance the early-age strength development of concrete containing bagasse ash. This research is limited to a semi-adiabatic temperature rise experiment. Studies incorporating isothermal calorimetry and adiabatic temperature rise experiment should follow through.

\section{Acknowledgements}

The Authors are very grateful to Addis Ababa University and Dr. Esayas Gebreyohannes for providing technical support. We are also appreciative to Wonji and Metehara Sugar factories for providing the SCBA.

\section{References}

[1] "Guide for the Use of Preplaced Aggregate Concrete for Structural and Mass Concrete Applications." ACI Materials Journal 88, no. 6 (1992). doi: 10.14359/1186.

[2] Bobko, Christopher P., Andrew J. Edwards, Rudolf Seracino, and Paul Zia. "Thermal Cracking of Mass Concrete Bridge Footings in Coastal Environments.” Journal of Performance of Constructed Facilities 29, no. 6 (December 2015): 04014171. doi: $10.1061 /$ (asce)cf.1943-5509.0000664.

[3] Lagundžija, Sandra, and Marie Thiam. 2017. "Temperature Reduction during Concrete Hydration in Massive Structures," $1-118$.

[4] ACI Committee 116. 2000. "ACI 116R-90. Cement and Concrete Terminology." American Concrete Institute, 58. http://dl.mycivil.ir/dozanani/ACI/ACI 116R-00 Cement and Concrete Terminology_MyCivil.ir.pdf.

[5] National Ready Mixed Concrete Association. 2009. "Thermal cracking of concrete". Technical information. Silver Spring, USA.

[6] Ulm, Franz-Josef, and Olivier Coussy. "Couplings in Early-Age Concrete: From Material Modeling to Structural Design." International Journal of Solids and Structures 35, no. 31-32 (November 1998): 4295-4311. doi: 10.1016/s0020-7683(97)00317-x.

[7] Jason Lee Meadows. 2007. "EARLY-AGE CRACKING OF MASS CONCRETE STRUCTURES.” Journal of Chemical
Information and Modeling.

[8] Siddique, Rafat, and Mohammad Iqbal Khan. "Metakaolin." Engineering Materials (2011): 175-230. doi: 10.1007/978-3-642-17866-5_4.

[9] Kim, Soo Geun. "Effect of Heat Generation from Cement Hydration on Mass Concrete Placement" (n.d.). doi: 10.31274/etd-180810-763.

[10] Moses, Priji E B, and Perumal. 2016. "Hydration of Cement and Its Mechanisms." IOSR Journal of Mechanical and Civil Engineering Ver. I 13 (6): 2278-1684. https://doi.org/10.9790/1684-1306011731.

[11] Geremew, Miheret. 2017. "Bagasse Ash as a Partial Substitute of Cement on Concrete Rigid Pavement." Addis Ababa University.

[12] Chini, A. R., and A. Parham. 2005. "Adiabatic Temperature Rise of Mass Concrete in Florida." Proceedings of the 1st International Conference on Recent Advances in Concrete Technology, RAC 2007.

[13] Belie, Nele De, Marios Soutsos, and Elke Gruyaert. 2018. Properties of Fresh and Hardened Concrete Containing Supplementary Cementitious Materials: State-of-the-Art Report of the RILEM Technical Committee 238-SCM, Working Group 4. https://doi.org/10.1007/978-3-319-70606-1_3.

[14] Shubham Srivastava, Puneet Kumar Shukla, Piyush Kumar, Kamal Kumar. 2015. "Feasibility of Partial Replacement of Cement By Sugarcane Bagasse Ash in Concrete.” I-Manager's $\begin{array}{llll}\text { Journal on Civil Engineering } 8 & \text { (3): } 38 .\end{array}$ https://doi.org/10.26634/jce.8.3.14450.

[15] Mahmud, Safayat, Md. Imamul Islam, Rubieyat Bin Ali, Md. Mofizul Islam, and Md. Mahadi Hasan. "Compressive Behaviour of Concrete by Using Bagasse Ash From Sugar Mill." Journal of Science and Technology 10, no. 3 (December 1, 2018). doi: 10.30880/jst.2018.10.03.008.

[16] Jahanzaib Khalil, Muhammad, Muhammad Aslam, and Sajjad Ahmad. 2021. "Utilization of Sugarcane Bagasse Ash as Cement Replacement for the Production of Sustainable Concrete - A Review." Construction and Building Materials https://doi.org/10.1016/j.conbuildmat.2020.121371.

[17] Rukzon, Sumrerng, and Prinya Chindaprasirt. 2012. "Utilization of Bagasse Ash in High-Strength Concrete." Materials and Design 34: 45-50. https://doi.org/10.1016/j.matdes.2011.07.045.

[18] Bayapureddy, Yogitha, Karthikeyan Muniraj, and Muni Reddy Gangireddy Mutukuru. 2020. "Sugarcane Bagasse Ash as Supplementary Cementitious Material in Cement Composites: Strength, Durability, and Microstructural Analysis.” Journal of the Korean Ceramic Society 57 (5): 513-19. https://doi.org/10.1007/s43207-020-00055-8.

[19] Amin, Noor-ul. 2011. "Use of Bagasse Ash in Concrete and Its Impact on the Strength and Chloride Resistivity." Journal of Materials in Civil Engineering 23 (5): 717-20. https://doi.org/10.1061/(asce)mt.1943-5533.0000227.

[20] Mangi, Sajjad Ali, N. Jamaluddin, M. H. Wan Ibrahim, Abd Halid Abdullah, A. S. M. Abdul Awal, Samiullah Sohu, and Nizakat Ali. 2017. "Utilization of Sugarcane Bagasse Ash in Concrete as Partial Replacement of Cement." IOP Conference Series: Materials Science and Engineering 271 (1). https://doi.org/10.1088/1757-899X/271/1/012001. 
[21] Shuaibu, R. A., T. Nyomboi, and R. N. Mutuku. "Shear Strength of Reinforced Sugarcane Bagasse Ash-Laterised Concrete Beams." Australian Journal of Structural Engineering 16, no. 3 (September 2, 2015): 199-207. doi: $10.1080 / 13287982.2015 .1092682$.

[22] Rerkpiboon, Aukkadet, Weerachart Tangchirapat, and Chai Jaturapitakkul. "Strength, Chloride Resistance, and Expansion of Concretes Containing Ground Bagasse Ash." Construction and Building Materials 101 (December 2015): 983-989. doi: 10.1016/j.conbuildmat.2015.10.140.

[23] Wu, K. 2014. Experimental Study on the Influence of ITZ on the Durability of Concrete Made with Different Kinds of Blended Materials.

[24] Xiong, Guangjing, Jinwei Liu, Gengying Li, and Huicai Xie. 2002. "A Way for Improving Interfacial Transition Zone between Concrete Substrate and Repair Materials." Cement and Concrete Research 32 (12): 1877-81. https://doi.org/10.1016/S0008-8846(02)00840-2.

[25] Neville, Adam M. 2011. The Properties of Concrete. Pearson Education Limited. 5th editio. Vol. 65. Pearson Education Limited. https://doi.org/10.11129/detail.9783034614740.19.

[26] Cordeiro, G. C., R. D. Toledo Filho, L. M. Tavares, and E. M. R Fairbairn. 2008. "Pozzolanic Activity and Filler Effect of Sugar Cane Bagasse Ash in Portland Cement and Lime Mortars." Cement and Concrete Composites 30 (5): 410-18. https://doi.org/10.1016/j.cemconcomp.2008.01.001.
[27] Kroehong, Wunchock, Theerawat Sinsiri, and Chai Jaturapitakkul. 2011. "Effect of Palm Oil Fuel Ash Fineness on Packing Effect and Pozzolanic Reaction of Blended Cement Paste." Procedia Engineering 14 (December): 361-69. https://doi.org/10.1016/j.proeng.2011.07.045.

[28] Kaleta-Jurowska, Alina, and Krystian Jurowski. 2020. "The Influence of Ambient Temperature on High Performance Concrete Properties." Materials 13 (20): 1-16. https://doi.org/10.3390/ma13204646.

[29] Soutsos, Marios, and Fragkoulis Kanavaris. "The Modified Nurse-Saul (MNS) Maturity Function for Improved Strength Estimates at Elevated Curing Temperatures." Case Studies in Construction Materials 9 (December 2018): e00206. doi: 10.1016/j.cscm.2018.e00206.

[30] Ginn, Samuel, Eric D Gross, Andrew D Eiland, Anton K Schindler, and Robert W Barnes. 2017. "Temperature Control Requirements for the Construction of Mass Concrete Members," no. December.

[31] Ribeiro, Bruno, Takashi Yamamoto, and Yosuke Yamashiki. "A Study on the Reduction in Hydration Heat and Thermal Strain of Concrete with Addition of Sugarcane Bagasse Fiber." Materials 13, no. 13 (July 6, 2020): 3005. doi: 10.3390/ma13133005. 